\title{
Public expenditure spillovers: an explanation for heterogeneous tax reaction functions
}

\author{
Rosella Levaggi ${ }^{1}$ (D) Paolo M. Panteghini ${ }^{2,3}$
}

Published online: 4 September 2020

(c) The Author(s) 2020

\begin{abstract}
In this article, we show that spillovers may provide an alternative explanation for the heterogeneity of tax reaction functions under tax competition. In particular, we assume the existence of $n \geq 2$ jurisdictions, which compete to attract mobile capital in a context where public expenditure produces spillovers. We show that the latter can lead to asymmetric responses. For instance, jurisdiction $i$ may react positively to a change in the tax rate of jurisdiction $j$ and negatively to the change in jurisdiction $z$. From a policy point of view, these findings are helpful to understand the mixed results found by the empirical literature, and to analyse the tax reaction functions of city centres and suburban jurisdictions.
\end{abstract}

Keywords Tax competition · Spillovers · Asymmetric reaction Functions

JEL Classification $\mathrm{H} 25 \cdot \mathrm{H} 2 \cdot \mathrm{H} 4$

Rosella Levaggi

rosella.levaggi@unibs.it

Paolo M. Panteghini

paolo.panteghini@unibs.it

1 Department of Economics and Management, University of Brescia, Via San Faustino 74b, 25122 Brescia, Italy

2 Department of Economics and Management, AccounTax Lab, University of Brescia, Brescia, Italy

3 CESifo, Munich, Germany 


\section{Introduction}

It is well known that mobility of productive factors may affect government fiscal strategies. This phenomenon distorts trade and investment patterns; it erodes national tax bases and shifts part of the tax burden onto less mobile tax bases. For this reason, economists have extensively analysed tax strategies since the pioneering articles by Zodrow and Mieszkowski (1986) and Wilson (1986). ${ }^{1}$ It is also well known and widely acknowledged that public goods and services may produce both positive and negative spillovers (their existence being well documented by Revelli 2005; Ojede et al. 2018; López et al. 2017; Solé-Ollé 2006; Banzhaf and Chupp 2011; Oates 2002; Ogawa and Wildasin 2009; Oates 2008). Surprisingly, little research deals with the interactions between these two phenomena. We argue that spillovers affect fiscal strategies; their inclusion in tax competition analysis may enrich our understanding of tax competition.

The theoretical literature on tax competition shows that when rates are strategic tools, strategic complementarity or strategic substitutability may arise. Despite these efforts, there is agreement neither on the sign of the reaction functions nor on their magnitude (see, for example, Leibrecht and Hochgatterer 2012). The literature shows that tax rates are in most cases strategic complements at an international level (see Devereux et al. 2008; Redoano 2014; Egger and Raff 2015), while they are likely to be strategic substitutes at sub-national or sub-federal level (e.g. Chirinko and Wilson 2017; Parchet 2019). Accordingly, Brueckner and Saavedra (2001) show that strategic substitution may occur when governments maximize a linear utility function, if the marginal value of private goods exceeds that of public goods. Mintz and Tulkens (1986) show that tax rates may be strategic substitutes if private consumption and public goods are complements. A similar result can be obtained if jurisdictions use public spending (instead of taxes) as their relevant strategic tool (see, for example, Wildasin 1988). ${ }^{2}$ More recently, Vrijburg and de Mooij (2016) have shown that the slope of the reaction functions depends on the jurisdiction's objective function. If countries maximize tax revenues, the slope of the reaction functions is always positive; on the other hand, if jurisdictions maximize welfare, a negative slope (denoting that tax rates are strategic substitutes) can be obtained. Parchet (2019) assumes that individuals (rather than capital) are mobile across jurisdictions. In this framework, the author finds that a residence-based personal income tax can be either a strategic substitute or complement, depending on the magnitude of the marginal utility of the local public good. In general, these findings crucially depend on the definition of the objective function and on the assumptions about technology; the common feature is that strategic complementarity and substitutability do not coexist. Household mobility and spillovers effects also characterize the relationship between sub-metropolitan

\footnotetext{
1 Given the heterogeneity among jurisdictions, since the beginning of $1990 \mathrm{~s}$ the literature has also focused on asymmetric tax competition. See, for example, Wilson (1991), Bucovetsky (1991), Kanbur and Keen (1993).

${ }^{2}$ On this topic, see, for example, Keen and Konrad (2013) who have provided an interesting review of the tax competition literature.
} 
areas where capital, residents and workers are mobile (see Ly 2018 and references therein).

A recent paper by Miniaci et al. (2018) has instead shown that strategic complementarity (with a positive slope of reaction functions) may coexist with strategic substitutability. In this article, we show that spillovers may provide an alternative explanation for tax asymmetry. In particular, we will show that strategic complementarity and substitutability can coexist. The fiscal federalism literature usually models positive spillovers, but negative externalities are also plausible. ${ }^{3}$ Public infrastructure usually causes negative spillovers (Boarnet 1998; Sloboda and Yao 2008). Negative externalities are also common in the environmental protection literature (Banzhaf and Chupp 2011; Oates 2002; Ogawa and Wildasin 2009). Moreover, expenditure programmes, particularly those intrinsically related to citizen welfare, may produce both positive and negative externalities to other regions. Brekke et al. (2016) show that if regions differ in income, public health care expenditure of rich regions may negatively affect welfare of the poorer region through patients' mobility. Furthermore, in Italy the payment of extra-regional hospital admission has generated additional amounts of financial flows in favour of central-northern regions, exacerbating the North-South gradient (see Cergas-Bocconi 2017). Given this evidence, we show that spillovers may lead to asymmetric effects, where strategic complementarity can coexist with strategic substitutability in tax competition. Since tax competition may be more complex than one might think, policy-makers should be aware of this. Our model may also allow to study the relationship between cities and suburban jurisdictions in a new light. Suburban jurisdictions are in fact going to benefit from the public good of the city centre, while the opposite may be less true. This has important consequences for tax competition that the literature has not fully explored so far.

The rest of the paper is organized as follows: Section 2 presents the model, where $n \geq 2$ jurisdictions aim at maximizing their own welfare, under full capital mobility and public expenditure spillovers. Section 3 analyses the reaction functions with spillovers and highlights their heterogeneity. In order to focus on spillover effects, Sect. 4 provides a simple model with three jurisdictions. Our main findings will then be discussed. Section 5 summarizes our results and discusses their policy implications.

\section{The model}

The model presented here focuses on tax competition in a context where public expenditure produces spillovers. In particular, we let $n \geqslant 2$ jurisdictions choose strategically their tax policies. Each of them is inhabited by a representative consumer and a representative firm. Two goods are produced:

\footnotetext{
3 According to Solé-Ollé (2006), in Spain one Euro of local spending provides the same utility to a typical resident as three Euro of neighbours'spending.
} 
1. a private good $C^{i}$, homogeneous across countries, whose price is equal to one and acts as numeraire in this simplified economy;

2. a public good $g^{i}$ which may produce spillovers across countries at rate $\beta$. Spillovers are assumed to be jurisdiction-specific.

In order to focus on spillovers and in line with Wildasin (1988), we define a production function that uses capital as a variable and fully mobile input. Other factors are assumed to be fixed and jurisdiction-specific; the functional form is homogeneous across jurisdictions and follows the Inada conditions. As in Wildasin (2001), citizens cannot change their residence, but cross-border shopping is allowed. Spillovers may also arise because of public services consumed by residents in other jurisdictions. ${ }^{4}$

Private good $C^{i}$ can be either consumed or used to produce the public good $g^{i}$. We can therefore measure the production of the public good in terms of private foregone consumption. The public good is homogeneous within each jurisdiction, but it may be heterogeneous across jurisdictions. The provision of public goods is financed by a source-based tax on capital. Given the tax rate $t^{i}$ and the capital invested in jurisdiction $i$, i.e. $K^{i}$, the balanced budget constraint for jurisdiction $i$ will then be equal to $g^{i}=t^{i} K^{i}$ and firm $i$ 's after-tax profit can be written as:

$$
\Pi_{i}=F\left(K^{i}\right)-\left(R(\mathbf{t})+t^{i}\right) K^{i},
$$

where $R(\mathbf{t})$ is the equilibrium net interest rate and $\mathbf{t}$ is the vector of tax rates applied in the $n$ jurisdictions.

The total quantity of capital across jurisdiction is fixed. By defining $\bar{K}^{i}$ as the capital endowment of jurisdiction $i$, the market-clearing condition $\sum_{i=1}^{n} K^{i}=\sum_{i=1}^{n} \bar{K}^{i}$ holds. Consumer $i$ is endowed with capital $\bar{K}^{i}$; she earns the after-tax profit of the local firm and a return equal to $R(\mathbf{t})$ times her capital endowment. Consumer $i$ 's budget constraint will be equal to:

$$
\begin{aligned}
C^{i} & =\left[F\left(K^{i}\right)-\left(R(\mathbf{t})+t^{i}\right) K^{i}\right]+R(\mathbf{t}) K^{i}+R(\mathbf{t}) \bar{K}^{i} \\
& =\left[F\left(K^{i}\right)-\left(R(\mathbf{t})+t^{i}\right) K\right]+R(\mathbf{t}) \bar{K}^{i}
\end{aligned}
$$

Consumer utility depends on the quantity of private good they can consume and on the level of the public good produced. Moreover, we assume that public expenditure produces spillovers, so that the utility function is

$$
U_{i}=U\left(C^{i}, G^{i}\right)
$$

where

\footnotetext{
${ }^{4}$ Parchet (2019) uses an original model which assumes the existence of a residence-based personal income tax and labour mobility. In this article, we prefer to follow the mainstream literature (according to which capital is the mobile factor and a source-based tax is levied). In doing so, a comparison with standard results is feasible. Anyway, the introduction of spillover effects as in Parchet (2019) might be an interesting extension worth pursuing.
} 


$$
G^{i}=g^{i}+\sum_{j \neq i} \beta_{i j} g^{j} .
$$

and $\beta_{i j} \gtrless 0$ measures the sign and magnitude of the spillover effect of jurisdiction $j$ 's public spending on consumer $i$ 's utility.

\subsection{Capital allocation}

Each firm employs the quantity of capital $K^{i}$ that maximizes its after-tax profit in (1). The demand for capital in each jurisdiction is obtained through the first-order conditions of the problem above. Since the firm takes $R(\mathbf{t})$ as given, the F.O.C. will be:

$$
\begin{aligned}
\Pi_{K} & =F_{K}\left(K^{i}\right)-\left(R(\mathbf{t})+t^{i}\right)=0 \\
F_{K}\left(K^{i}\right) & =R(\mathbf{t})+t^{i} .
\end{aligned}
$$

To analyse the effects of taxation on the investment choices, we differentiate (5) with respect to $t^{i}$ thereby obtaining:

$$
\begin{aligned}
\frac{\partial K^{i}}{\partial t^{i}} & =\frac{1+\frac{\partial R(\mathbf{t})}{\partial t^{i}}}{F_{K K}\left(K^{i}\right)}, \\
\frac{\partial K^{j}}{\partial t^{i}} & =\frac{\frac{\partial R(\mathbf{t})}{\partial t^{i}}}{F_{K K}\left(K^{j}\right)} \text { with } j \neq i .
\end{aligned}
$$

Given these results, we can write the following:

Lemma 1 The inequalities $-1<\frac{\partial R(\mathbf{t})}{\partial t^{i}}<0, \frac{\partial K^{i}}{\partial t^{i}}<0$ and $\frac{\partial K^{j}}{\partial t^{i}}>0$ hold. $\frac{\partial R(\mathbf{t})}{\partial t^{i}}=0$ only if $n$ goes to infinity.

Proof See Appendix 1.

\subsection{Government problem}

Government chooses the tax rate that maximizes the utility of its consumer. The problem for jurisdiction $i$ can be written as:

$$
\begin{aligned}
\operatorname{Max}_{t^{i}} U_{i}= & U\left(C^{i}, G^{i}\right) \\
& \text { s.t. } \\
G^{i}= & g^{i}+\sum_{j \neq i} \beta_{i j} g^{j}, \\
g^{i}= & t^{i} K^{i} \text { and } g^{j}=t^{j} K^{j} \text { for any } j \neq i, \\
C^{i}= & {\left[F\left(K^{i}\right)-\left(R(\mathbf{t})+t^{i}\right) K\right]+R(\mathbf{t}) \bar{K}^{i} . }
\end{aligned}
$$

Using (2) and (4), the F.O.C. can be written as: 


$$
\begin{gathered}
U_{C^{i}}\left(C^{i}, G^{i}\right) \frac{\partial C^{i}}{\partial t}+U_{G^{i}}\left(C^{i}, G^{i}\right) \frac{\partial G^{i}}{\partial t}=0, \\
\frac{U_{G^{i}}\left(C^{i}, G^{i}\right)}{U_{C^{i}}\left(C^{i}, G^{i}\right)}=-\frac{\frac{\partial C^{i}}{\partial t^{i}}}{\frac{\partial G^{i}}{\partial t^{i}}}
\end{gathered}
$$

where

$$
\begin{aligned}
\frac{\partial C^{i}}{\partial t^{i}} & =\left[F_{K}\left(K^{i}\right)-\left(R(\mathbf{t})+t^{i}\right)\right] \frac{\partial K^{i}}{\partial t^{i}}-\left(1+\frac{\partial R(\mathbf{t})}{\partial t^{i}}\right) K^{i}+\frac{\partial R(\mathbf{t})}{\partial t^{i}} \bar{K}^{i} \\
& =-K^{i}-\left(K^{i}-\bar{K}^{i}\right) \frac{\partial R(\mathbf{t})}{\partial t^{i}}, \\
\frac{\partial G^{i}}{\partial t^{i}} & =K^{i}+t^{i} \frac{\partial K^{i}}{\partial t^{i}}+\sum_{j \neq i} \beta_{i j} t^{j} \frac{\partial K^{j}}{\partial t^{i}} .
\end{aligned}
$$

We therefore obtain:

$$
\frac{U_{G^{i}}\left(C^{i}, G^{i}\right)}{U_{C^{i}}\left(C^{i}, G^{i}\right)} \equiv M R S^{i}=\frac{1+\left(1-\frac{\bar{K}^{i}}{K^{i}}\right) \frac{\partial R(\mathbf{t})}{\partial t^{i}}}{1-\sum_{j \neq i}\left(1-\beta_{i j} \frac{t^{i}}{t^{i}}\right) \varepsilon^{i j}}
$$

with $\varepsilon^{i} \equiv \frac{t^{i}}{K^{i}} \frac{\partial K^{i}}{\partial t^{i}}<0$ and $\varepsilon^{i j} \equiv \frac{t^{i}}{K^{i}} \frac{\partial K^{j}}{\partial t^{i}}$ with $\varepsilon^{i} \equiv \frac{t^{i}}{K^{i}} \frac{\partial K^{i}}{\partial t^{i}}=-\sum_{j \neq i} \varepsilon^{i j} \equiv-\sum_{j \neq i} \frac{t^{i}}{K^{i}} \frac{\partial K^{j}}{\partial t^{i}}<0$.

The inequality $M R S^{i} \gtrless 1$ depends on technology, tax rates and whether a country is a capital importer or exporter. In particular $\left(1-\frac{\bar{K}^{i}}{K^{i}}\right) \frac{\partial R(\mathbf{t})}{\partial t^{i}}$ is positive (negative) if country $i$ is a capital importer (exporter)..$^{5}$ Moreover, the equilibrium condition is affected by both the magnitude and sign of spillover effects. Since $\varepsilon^{i j} \propto \frac{t^{j}}{t^{i}}>0$, the sign of $\sum_{j \neq i} \beta_{i j} \frac{t^{j}}{t^{i}} \varepsilon^{i j}$ crucially depends on the spillover parameters $\beta_{i j}$ with $j^{t^{i}} \neq i$.

\section{Reaction functions}

In order to study the sign of reaction functions around the equilibrium, we assume that $t^{i}$ changes and calculate its effect on the tax rate of a generic country $j \neq i$. Applying the envelope theorem, we differentiate (9) w.r.t. $t^{j}$ and $t^{i}$ around the equilibrium value of $M R S^{i}$. As shown in Appendix 2, we obtain:

$$
\frac{\mathrm{d} t^{j}}{\mathrm{~d} t^{i}}=\frac{M R S^{i}\left[\frac{t^{j} \varepsilon^{i j} \beta_{i j}}{\left(t^{i}\right)^{2}}+\left(1-\beta_{i j} \frac{t^{j}}{t^{i}}\right) \frac{\partial \varepsilon^{i j}}{\partial t^{i}}\right]+\left[\left(1-\frac{\bar{K}^{i}}{K^{i}}\right) \frac{\partial R^{2}(\mathbf{t})}{\partial t^{i} \partial t^{i}}+\frac{\bar{K}^{i}}{\left(K^{i}\right)^{2}} \frac{\partial R(\mathbf{t})}{\partial t^{i}} \frac{\partial K^{i}}{\partial t^{i}}\right]}{M R S^{i}\left[\frac{\varepsilon^{i j} \beta_{i j}}{t^{i}}-\left(1-\beta_{i j} \frac{t^{j}}{t^{i}}\right) \frac{\partial \varepsilon^{i j}}{\partial t^{j}}\right]-\left[\left(1-\frac{\bar{K}^{i}}{K^{i}}\right) \frac{\partial^{2} R(\mathbf{t})}{\partial t^{i} \partial t^{j}}+\frac{\bar{K}^{i}}{\left(K^{i}\right)^{2}} \frac{\partial R(\mathbf{t})}{\partial t^{i}} \frac{\partial K^{i}}{\partial t^{j}}\right]},
$$

\footnotetext{
5 For more details, see Ogawa (2007).
} 
with $\varepsilon^{i j} \equiv \frac{t^{i}}{K^{i}} \frac{\partial K^{j}}{\partial t^{i}}>0, \frac{\partial \varepsilon^{i j}}{\partial t^{i}}=\frac{1}{K^{i}}\left[\frac{\partial K^{j}}{\partial t^{i}}\left(1-\varepsilon^{i j}\right)+t^{i} \frac{\partial^{2} K^{j}}{\left(\partial t^{i}\right)^{2}}\right]$ and $\frac{\partial \varepsilon^{i j}}{\partial t^{j}}=\frac{t^{i}}{K^{i}} \frac{\partial^{2} K^{j}}{\partial t^{i} \partial t^{j}}$. As can be seen, $\frac{\mathrm{d} t^{j}}{\mathrm{~d} t^{i}}$ can be positive or negative according to the sign and magnitude of the different spillover effects. It is worth noting that with a quadratic production function, we have $\frac{\partial R^{2}(\mathbf{t})}{\partial t^{i} \partial t^{i}}=\frac{\partial^{2} R(\mathbf{t})}{\partial t^{i} \partial t^{j}}=\frac{\partial^{2} K^{j}}{\left(\partial t^{i}\right)^{2}}=0$ and (10) reduces to:

$$
\frac{\mathrm{d} t^{j}}{\mathrm{~d} t^{i}}=\frac{M R S^{i}\left[\frac{t^{j} \varepsilon^{i j} \beta_{i j}}{\left(t^{i}\right)^{2}}+\left(1-\beta_{i j} \frac{t^{j}}{t^{i}}\right) \frac{\partial \varepsilon^{i j}}{\partial t^{i}}\right]+\left[\frac{\bar{K}^{i}}{\left(K^{i}\right)^{2}} \frac{\partial R(\mathbf{t})}{\partial t^{i}} \frac{\partial K^{i}}{\partial t^{i}}\right]}{M R S^{i}\left[\frac{\varepsilon^{i j} \beta_{i j}}{t^{i}}-\left(1-\beta_{i j} \frac{t^{j}}{t^{i}}\right) \frac{\partial \varepsilon^{i j}}{\partial t^{j}}\right]-\left[\frac{\bar{K}^{i}}{\left(K^{i}\right)^{2}} \frac{\partial R(\mathbf{t})}{\partial t^{i}} \frac{\partial K^{i}}{\partial t^{j}}\right]},
$$

with $\frac{\partial \varepsilon^{i j}}{\partial t^{i}}=\frac{1}{K^{i}}\left[\frac{\partial K^{j}}{\partial t^{i}}\left(1-\varepsilon^{i j}\right)\right]$. As can be seen, (11) is still heterogeneous. For this reason, we propose a simplified example, where not only the production function is quadratic, but also the consumer utility is linear.

\section{A simplified model}

We consider the optimal choice of tax rates for governments with $n=3$, a quadratic production function:

$$
f\left(K^{i}\right)=\left(b_{i}\left(a_{i}-K^{i}\right) K^{i}\right) \quad i=1,2,3,
$$

where $b_{i}$ and $a_{i}$ are the jurisdiction-specific productivity parameters, and $K^{i}$ is capital, with $f\left(K^{i}\right) \geq 0$, i.e. $K^{i} \leq \frac{b_{i} a_{i}}{2}$. As in Bjorvatn and Schjelderup (2002), a linear utility in $C^{i}$ and $g^{i}$ (with $i=1,2,3$ ) is applied:

$$
U_{i}=\alpha_{i} C^{i}+\left(1-\alpha_{i}\right)\left(g^{i}+\sum_{i \neq j}^{n} \beta_{i j} g^{j}\right)
$$

where $\alpha_{i}$ and $\left(1-\alpha_{i}\right)$ are the relative weight for private consumption and public good, respectively.

\subsection{Reaction functions}

The reaction functions of each jurisdiction to a change in the tax rate of the other local authorities can be written as (see "Reaction functions" in Appendix): 


$$
\begin{aligned}
& t^{12}=b_{3} \frac{\alpha_{1} b_{1}\left(b_{3}+b_{2}\right)-\Theta\left(1-\alpha_{1}\right)\left(1+\beta_{12}\right)}{-\left(b_{3}+b_{2}\right)\left(2 \Theta\left(1-\alpha_{1}\right)-\alpha_{1} b_{1}\left(b_{3}+b_{2}\right)\right)}, \\
& t^{13}=b_{2} \frac{\alpha_{1} b_{1}\left(b_{3}+b_{2}\right)-\Theta\left(1-\alpha_{1}\right)\left(1+\beta_{13}\right)}{-\left(b_{3}+b_{2}\right)\left(2 \Theta\left(1-\alpha_{1}\right)-\alpha_{1} b_{1}\left(b_{3}+b_{2}\right)\right)}, \\
& t^{21}=b_{3} \frac{\alpha_{2} b_{2}\left(b_{3}+b_{1}\right)-\Theta\left(1-\alpha_{2}\right)\left(1+\beta_{21}\right)}{-\left(b_{1}+b_{3}\right)\left(2 \Theta\left(1-\alpha_{2}\right)-\alpha_{2}\left(b_{2} b_{3}+b_{2} b_{1}\right)\right)}, \\
& t^{23}=b_{1} \frac{\alpha_{2} b_{2}\left(b_{3}+b_{1}\right)-\Theta\left(1-\alpha_{2}\right)\left(1+\beta_{23}\right)}{-\left(b_{1}+b_{3}\right)\left(2 \Theta\left(1-\alpha_{2}\right)-\alpha_{2}\left(b_{2} b_{3}+b_{2} b_{1}\right)\right)}, \\
& t^{31}=b_{2} \frac{\alpha_{3} b_{3}\left(b_{1}+b_{2}\right)-\Theta\left(1-\alpha_{3}\right)\left(1+\beta_{31}\right)}{-\left(b_{1}+b_{2}\right)\left(2 \Theta\left(1-\alpha_{3}\right)-\alpha_{3} b_{3}\left(b_{1}+b_{2}\right)\right)}, \\
& \frac{\alpha_{3} b_{3}\left(b_{1}+b_{2}\right)-\Theta\left(1-\alpha_{3}\right)\left(1+\beta_{32}\right)}{-\left(b_{1}+b_{2}\right)\left(2 \Theta\left(1-\alpha_{3}\right)-\alpha_{3} b_{3}\left(b_{1}+b_{2}\right)\right)} .
\end{aligned}
$$

The sign of the reaction functions can be either positive or negative: this depends on the characteristics of the objective function (preferences and technology) as well as on spillovers. The interesting feature of these reaction functions is that spillovers allow jurisdictions to have asymmetric responses in two dimensions: (a) reciprocal (i.e. $t^{i j}$ may be different from $t^{j i}$ ); (b) across jurisdictions (i.e. the signs of $t^{i j}$ may be different from the signs of $t^{i z}$ and $t^{j z}$ and at the same time the signs of $t^{i z}$ and $t^{j z}$ may also be different).

To show this, let us consider the reaction function of $t^{1}$ to a change in $t^{2}$ and $t^{3}$. Given $v_{i} \equiv b_{i}\left(\sum_{j \neq i} b_{j}\right)$ and $\Theta \equiv\left(b_{1} b_{3}+b_{2} b_{3}+b_{2} b_{1}\right)$, in "Proof of inequalities (15)" in Appendix we show that:

$$
\begin{aligned}
& t^{12} \gtrless 0 \text { if } \beta_{12} \gtrless \frac{\alpha_{1}}{1-\alpha_{1}} \frac{v_{1}}{\Theta}-1, \\
& t^{13} \gtrless 0 \text { if } \beta_{13} \gtrless \frac{\alpha_{1}}{1-\alpha_{1}} \frac{v_{1}}{\Theta}-1 .
\end{aligned}
$$

This means that with heterogeneous spillover effects, strategic complementarity and substitutability can coexist. If, for instance, $\beta_{12}>\frac{\alpha_{1}}{1-\alpha_{1}} \frac{v_{1}}{\Theta}-1>\beta_{13}$, we obtain $t^{12}>0>t^{13}$. In other words, $t^{1}$ and $t^{2}$ are strategic complements, whereas $t^{1}$ and $t^{3}$ are strategic substitutes. This result is sufficient to prove that according to our model, tax convergence and tax divergence may coexist: namely, $t^{1}$ and $t^{2}$ move in the same direction, whereas $t^{1}$ and $t^{3}$ are diverging.

Our model allows us to interpret the results of the previous literature in a new light. For example, Vrijburg and de Mooij (2016) concludes that with a linear welfare function, strategic complementary always holds. We show that this is true only if there are no spillovers. If public expenditure produces spillovers, the story is rather different. Using (15) we can determine the following threshold value of the spillover effect:

$$
\overline{\beta_{i j}} \equiv \frac{\alpha_{i}}{1-\alpha_{i}} \cdot \frac{v_{i}}{\Theta}-1 \text {. }
$$


Since $\frac{v_{i}}{\Theta}<1$, the sign mostly depends on the shape of consumers' preferences $\left(\frac{\alpha_{i}}{1-\alpha_{i}}\right)$. For $\frac{\alpha_{i}}{1-\alpha_{i}}<1\left(\alpha_{i}<\frac{1}{2}\right)$ strategic substitution is compatible only with negative spillovers. However, for higher values of $\alpha$, strategic substitution may arise, even with positive spillovers. The intuition behind this result is straightforward: if public expenditure is relatively more important than private consumption (low $\alpha$ ), only a negative spillover is compatible with strategic substitution. If, however, private consumption is relatively more important (i.e. $\alpha$ is high enough), also positive spillovers can lead to strategic substitutability.

\subsection{Symmetric productivity parameters}

In order to get a better understanding of the impact of spillovers, let us consider a symmetric case where $b_{i}=b$. Under this assumption, the reaction function exists if $\alpha_{i} \neq \frac{3}{4}{ }^{6}$ For $\alpha_{i}>\frac{3}{4}$, the reaction function is always positive in this linear setting, whereas for $\alpha_{i}<\frac{3}{4}$ :

$$
t^{i j}=\frac{1}{2} \frac{3\left(1+\beta_{i j}\right)\left(1-\alpha_{i}\right)-2 \alpha_{i}}{6\left(1-\alpha_{i}\right)-2 \alpha_{i}} .
$$

Using (16) and setting $t^{i j}=0$ give the values of $\beta_{i j}$ and $\alpha_{i}$ such that the reaction function is zero:

$$
\beta_{i j}=\frac{2}{3} \frac{\alpha_{i}}{1-\alpha_{i}}-1 .
$$

Accordingly, if $\beta_{i j}>\frac{2}{3} \frac{\alpha_{i}}{1-\alpha_{i}}-1$, the reaction function is positive; otherwise, it is negative. Figure 1 provides a graphical explanation.

The blue line represents the different combinations of spillovers and preferences for the public good for which the slope of reaction functions is nil. Above (below) this line, the slope of the reaction function is positive (negative).

When spillovers are positive $\left(\beta_{i j} \geq 0\right)$, a change in the tax rate of other jurisdictions usually produces strategic complementarity if $\alpha$ is low enough. On the other hand, if spillovers are negative, the number of possible combinations of $(\alpha, \beta)$ for which the reaction function can be negative increases. All the points along the blue line show cases where a jurisdiction's tax rate is set independently from the behaviour of another jurisdiction. (This result is in line with Bjorvatn and Schjelderup 2002.) The points on the horizontal axis allow us to compare our results with Vrijburg and de Mooij (2016) (who set $\beta=0$ ): strategic complementarity (substitutability) holds if $\alpha$ is low (high) enough. Outside the horizontal axis and the blue line, we can find heterogeneous reaction functions, where strategic complementarity and substitutability can coexist even if technology is the same across jurisdictions.

Let us now analyse the implications for the slope of the reaction functions using some estimates of the spillovers effects from the literature. Solé-Ollé (2006)

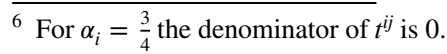




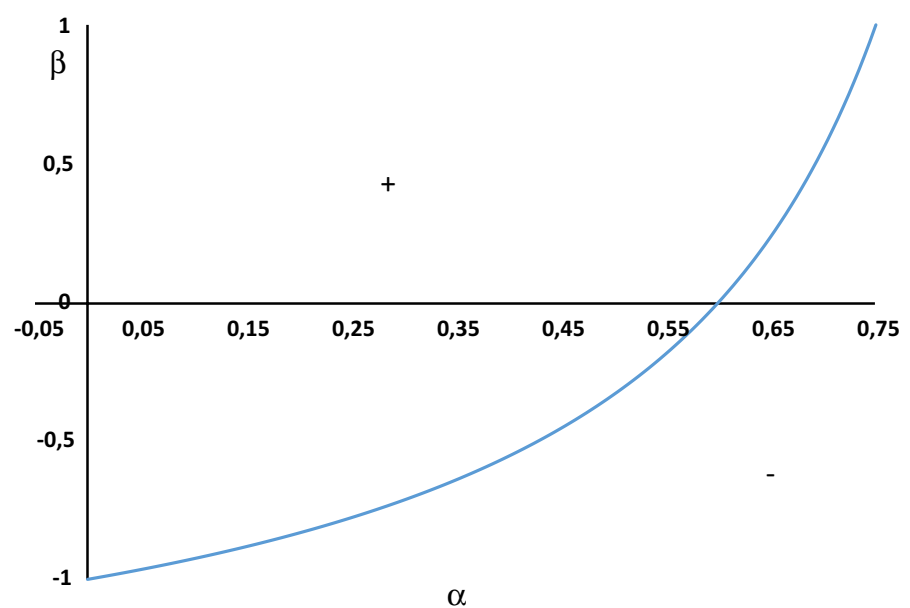

Fig. 1 Sign of the tax change for alternative combinations of $\beta$ and $\alpha$

estimated that expenditure spillovers for Spanish local jurisdictions range from 0 to $0.67 .^{7}$ For example, as shown in Figure 1 , if $\beta_{12}>0.6$ and $\beta_{13}<0.6$, an asymmetric effect would arise. Boarnet (1998) studies the spillover effects caused by public infrastructure on neighbouring local jurisdictions ${ }^{8}$ and finds spillover effects ranging from -0.506 to 0.24 . In this case, the likelihood of having reactions functions with different signs is even higher. Finally, Fondazione GiMBE (2019) show that in $201740.7 \%$ of Calabria's cancer patients chose to be treated elsewhere in Italy, while Lombardy received almost 17,000 cancer patients from other Italian regions. This flow allows Lombardy to save $€ 54$ out of a per capita expenditure of $€ 1877$. In other words, there is a positive spillover equal to $\frac{54}{1877+54}=0.028$. Let us next go back to Calabria: here every citizen pays $€ 1875$ per year for public health, of which $€ 126$ are used for health care provided outside the region boundaries. Hence, Calabria faces a negative spillover equal to $\frac{-126}{1875}=-0.0672$.

Of course, when technology is heterogeneous, the probability of coexistence of strategic complementarity and substitutability increases.

Our results show that there are potentially heterogeneous effects to be investigated: this may be an interesting avenue for empirical research. In particular, it is likely that the closer the jurisdictions, the stronger the spillovers are and the more likely heterogeneity of reaction functions is. Analogously, the empirical analysis in an urban setting might benefit from the results of our model: in this case, the joint study of urban

\footnotetext{
${ }^{7}$ López et al. (2017) study per capita expenditures of ten sub-programmes (Security, Housing, Welfare, Environment, Social services, Employment promotion, Health, Education, Culture and Sport) for Spanish municipalities. Interestingly, they find mixed effects: while spillover effects are positive for eight subprogrammes, when they focus on estimated residuals, five of them are negative. López et al. (2017) argue that "the cause that could generate a negative sign in the parameter of spatial dependence in the residuals is related to municipal policy decisions, which cannot be included in econometric modelling" (p. 63). Unfortunately, this evidence is hard to fit with our $\beta$ parameters.

8 Notice that investments need maintenance and therefore have an impact on current spending.
} 
and suburban jurisdictions might consider the benefits arising from provision of public goods. It is likely that the city centre would benefit more from such provisions. Hence, it would be interesting to analyse the tax reaction functions of both city centres and suburban jurisdictions (see, for example, Ly 2018).

\section{Conclusion}

While most of the traditional literature on fiscal federalism (Oates 2008) tends to associate spillovers with a positive effect, the empirical literature has shown many instances of negative externalities. Moreover, spillovers may not be reciprocal and may also have a different sign, as in health care. For this reason, this article has studied tax competition under spillover effects. We have shown that tax strategies may be heterogeneous. In particular, if spillover effects are negative (as in the case of health services trade, transportation and pollution), taxes are more likely to be strategic substitutes. In other words, with negative spillovers, the potential gain from attracting foreign capital is at least partially amplified by the loss from an external reduction in public goods supply. This means that if a jurisdiction levies a higher tax rate, other competing jurisdictions can find it optimal to react in different ways, by either cutting or increasing rates. Hence, strategic complementarity and substitutability can coexist.

Our results have important policy implications, in that they can explain the lack of tax convergence among jurisdictions. Moreover, according to our model, tax convergence and tax divergence may coexist for different subsets of jurisdictions.

Our model is based on many standard assumptions: source-based (rather than residence-based) taxation; capital (rather than labour) mobility, public expenditure as a consumption good (rather than a productive input) as well as horizontal (rather than multilevel) competition. Introducing labour mobility, a productive public expenditure and multilevel competition are all interesting avenues worth pursuing in future research.

Acknowledgements We would like to thank Prof. Enrico Minelli for his helpful comments. The usual disclaimer applies.

Funding Open access funding provided by Universit $\tilde{A}$ degli Studi di Brescia within the CRUI-CARE Agreement.

\section{Compliance with ethical standards}

Conflict of interest The authors declare that they have no conflict of interest.

Open Access This article is licensed under a Creative Commons Attribution 4.0 International License, which permits use, sharing, adaptation, distribution and reproduction in any medium or format, as long as you give appropriate credit to the original author(s) and the source, provide a link to the Creative Commons licence, and indicate if changes were made. The images or other third party material in this article are included in the article's Creative Commons licence, unless indicated otherwise in a credit line to the material. If material is not included in the article's Creative Commons licence and your intended use is not permitted by statutory regulation or exceeds the permitted use, you will need to obtain permission directly from the copyright holder. To view a copy of this licence, visit http://creativecommons.org/licen ses/by/4.0/. 


\section{Appendix 1: Proof of Lemma}

Proof Using (2), and (6) we can find the signs of $\frac{\partial R(\mathbf{t})}{\partial t^{i}}, \frac{\partial K^{i}}{\partial t^{i}}$ and $\frac{\partial K^{j}}{\partial t^{i}}$. Firstly, using (6) and summing up all the equations with $j \neq i$ give

$$
\begin{gathered}
\frac{\partial K^{j}}{\partial t^{i}}=\frac{\frac{\partial R(\mathbf{t})}{\partial t^{i}}}{F_{K K}\left(K^{j}\right)} \text { with } j \neq i \\
\sum_{j \neq i}^{n} \frac{\partial K^{j}}{\partial t^{i}}=\left[\sum_{j \neq i}^{n} \frac{1}{F_{K K}\left(K^{j}\right)}\right] \frac{\partial R(\mathbf{t})}{\partial t^{i}}
\end{gathered}
$$

and, given (2), the equality

$$
\frac{\partial K^{j}}{\partial t^{i}}+\sum_{j \neq i}^{n} \frac{\partial K^{j}}{\partial t^{i}}=0
$$

holds. Given (17), we therefore obtain:

$$
\begin{array}{r}
\frac{\partial K^{j}}{\partial t^{i}}+\sum_{j \neq i}^{n} \frac{\partial K^{j}}{\partial t^{i}}=\left[\sum_{j \neq i}^{n} \frac{1}{F_{K K}\left(K^{j}\right)}\right] \frac{\partial R(\mathbf{t})}{\partial t^{i}}+\frac{1+\frac{\partial R(\mathbf{t})}{\partial t^{i}}}{F_{K K}\left(K^{i}\right)}=0 \\
{\left[\sum_{j \neq i}^{n} \frac{1}{F_{K K}\left(K^{j}\right)}\right] \frac{\partial R(\mathbf{t})}{\partial t^{i}}+\frac{1+\frac{\partial R(\mathbf{t})}{\partial t^{i}}}{F_{K K}\left(K^{i}\right)}=0} \\
\frac{\partial R(\mathbf{t})}{\partial t^{i}}=-\frac{1 / F_{K K}\left(K^{i}\right)}{\sum_{j=1}^{n} \frac{1}{F_{K K}\left(K^{j}\right)}}=-\frac{1}{\frac{1}{F_{K K}\left(K^{i}\right)}+\sum_{j \neq i}^{n} \frac{1}{F_{K K}\left(K^{j}\right)}}<0
\end{array}
$$

Moreover, we can write

$$
\begin{aligned}
& \frac{\frac{1}{F_{K K}\left(K^{i}\right)}}{\frac{1}{F_{K K}\left(K^{i}\right)}+\sum_{j \neq i}^{n} \frac{1}{F_{K K}\left(K^{j}\right)}}<1 \\
& -\frac{\frac{1}{F_{K K}\left(K^{i}\right)}}{\frac{1}{F_{K K}\left(K^{i}\right)}+\sum_{j \neq i}^{n} \frac{1}{F_{K K}\left(K^{j}\right)}}>-1
\end{aligned}
$$

This means that $\frac{\partial R(\mathbf{t})}{\partial t^{i}} \in(-1,0){ }^{9}$

Qui dobbiamo inserire un riferimento alle derivate nel testo, prima del Lemma 1.

\section{Appendix 2: Derivation of Eq. (10)}

Using the envelope theorem, let us calculate the following derivative around the equilibrium:

\footnotetext{
$\overline{{ }^{9} \text { Under symmetry we have } \frac{\partial R(\mathbf{t})}{\partial t^{i}}}=-\frac{1}{n}$. Moreover, if $n$ goes to infinity, then $\frac{\partial R(\mathbf{t})}{\partial t^{i}}=0$.
} 


$$
\mathrm{d} M R S^{i}=\frac{\partial M R S^{i}}{\partial t^{i}} \mathrm{~d} t^{i}+\frac{\partial M R S^{i}}{\partial t^{j}} \mathrm{~d} t^{j}=0
$$

This gives:

$$
\begin{aligned}
& -\frac{1+\left(1-\frac{\bar{K}^{i}}{K^{i}}\right) \frac{\partial R(\mathbf{t})}{\partial t^{i}}}{\left[1-\sum_{j \neq i}\left(1-\beta_{i j} \frac{t^{j}}{t^{i}}\right) \varepsilon^{i j}\right]^{2}} \\
& \cdot\left[\left(\frac{1}{t^{i}} \varepsilon^{i j} \beta_{i j} \mathrm{~d} t^{j}-\frac{t^{j}}{\left(t^{i}\right)^{2}} \varepsilon^{i j} \beta_{i j} \mathrm{~d} t^{i}\right)-\left(1-\beta_{i j} \frac{t^{j}}{t^{i}}\right)\left(\frac{\partial \varepsilon^{i j}}{\partial t^{i}} \mathrm{~d} t^{i}+\frac{\partial \varepsilon^{i j}}{\partial t^{j}} \mathrm{~d} t^{j}\right)\right] \\
& +\frac{\left(1-\frac{\bar{K}^{i}}{K^{i}}\right)\left(\frac{\partial R^{2}(\mathbf{t})}{\partial t^{i} \partial t^{i}}\right)+\frac{\bar{K}^{i}}{\left(K^{i}\right)^{2}} \frac{\partial R(\mathbf{t})}{\partial t^{i}} \frac{\partial K^{i}}{\partial t^{i}}}{1-\sum_{j \neq i}\left(1-\beta_{i j} t^{\frac{t}{t^{i}}}\right) \varepsilon^{i j}} \mathrm{~d} t^{i}
\end{aligned}
$$

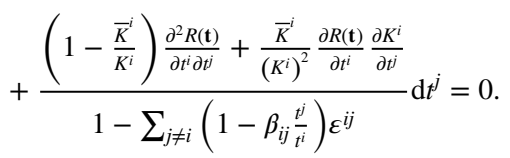

$$
\begin{aligned}
& -M R S^{i} \cdot\left[\left(\frac{1}{t^{i}} \varepsilon^{i j} \beta_{i j} \mathrm{~d} t^{j}-\frac{t^{j}}{\left(t^{i}\right)^{2}} \varepsilon^{i j} \beta_{i j} \mathrm{~d} t^{i}\right)-\left(1-\beta_{i j} \frac{t^{j}}{t^{i}}\right)\left(\frac{\partial \varepsilon^{i j}}{\partial t^{i}} \mathrm{~d} t^{i}+\frac{\partial \varepsilon^{i j}}{\partial t^{j}} \mathrm{~d} t^{j}\right)\right] \\
& +\left[\left(1-\frac{\bar{K}^{i}}{K^{i}}\right)\left(\frac{\partial R^{2}(\mathbf{t})}{\partial t^{i} \partial t^{i}}\right)+\frac{\bar{K}^{i}}{\left(K^{i}\right)^{2}} \frac{\partial R(\mathbf{t})}{\partial t^{i}} \frac{\partial K^{i}}{\partial t^{i}}\right] \mathrm{d} t^{i} \\
& +\left[\left(1-\frac{\bar{K}^{i}}{K^{i}}\right) \frac{\partial^{2} R(\mathbf{t})}{\partial t^{i} \partial t^{j}}+\frac{\bar{K}^{i}}{\left(K^{i}\right)^{2}} \frac{\partial R(\mathbf{t})}{\partial t^{i}} \frac{\partial K^{i}}{\partial t^{j}}\right] \mathrm{d} t^{j}=0 \\
& M R S^{i} \cdot\left[\frac{1}{t^{i}} \varepsilon^{i j} \beta_{i j} \mathrm{~d} t^{j}-\left(1-\beta_{i j} \frac{t^{j}}{t^{i}}\right) \frac{\partial \varepsilon^{i j}}{\partial t^{j}} \mathrm{~d} t^{j}-\frac{t^{j}}{\left(t^{i}\right)^{2}} \varepsilon^{i j} \beta_{i j} \mathrm{~d} t^{i}-\left(1-\beta_{i j} \frac{t^{j}}{t^{i}}\right) \frac{\partial \varepsilon^{i j}}{\partial t^{i}} \mathrm{~d} t^{i}\right] \\
& -\left[\left(1-\frac{\bar{K}^{i}}{K^{i}}\right)\left(\frac{\partial R^{2}(\mathbf{t})}{\partial t^{i} \partial t^{i}}\right)-\frac{\bar{K}^{i}}{\left(K^{i}\right)^{2}} \frac{\partial R(\mathbf{t})}{\partial t^{i}} \frac{\partial K^{i}}{\partial t^{i}}\right] \mathrm{d} t^{i} \\
& -\frac{\left(1-\frac{\bar{K}^{i}}{\bar{K}^{i}}\right) \frac{\partial^{2} R(\mathbf{t})}{\partial t^{i} \partial t^{j}}+\frac{\bar{K}^{i}}{\left(K^{i}\right)^{2}} \frac{\partial R(\mathbf{t})}{\partial t^{i}} \frac{\partial K^{i}}{\partial t^{i}}}{\left[1-\sum_{j \neq i}\left(1-\beta_{i j} \frac{t^{j}}{t^{i}}\right) \varepsilon^{i j}\right]} \mathrm{d} t^{j}=0 . \\
& M R S^{i} \cdot\left[\frac{1}{t^{i}} \varepsilon^{i j} \beta_{i j}-\left(1-\beta_{i j} \frac{t^{j}}{t^{i}}\right) \frac{\partial \varepsilon^{i j}}{\partial t^{j}}\right] \mathrm{d} t^{j} \\
& -\left[\left(1-\frac{\bar{K}^{i}}{K^{i}}\right) \frac{\partial^{2} R(\mathbf{t})}{\partial t^{i} \partial t^{j}}+\frac{\bar{K}^{i}}{\left(K^{i}\right)^{2}} \frac{\partial R(\mathbf{t})}{\partial t^{i}} \frac{\partial K^{i}}{\partial t^{j}}\right] \mathrm{d} t^{j} \\
& =M R S^{i}\left[\frac{t^{j}}{\left(t^{i}\right)^{2}} \varepsilon^{i j} \beta_{i j}+\left(1-\beta_{i j} \frac{t^{j}}{t^{i}}\right) \frac{\partial \varepsilon^{i j}}{\partial t^{i}}\right] \mathrm{d} t^{i} \\
& +\left[\left(1-\frac{\bar{K}^{i}}{K^{i}}\right)\left(\frac{\partial R^{2}(\mathbf{t})}{\partial t^{i} \partial t^{i}}\right)+\frac{\bar{K}^{i}}{\left(K^{i}\right)^{2}} \frac{\partial R(\mathbf{t})}{\partial t^{i}} \frac{\partial K^{i}}{\partial t^{i}}\right] \mathrm{d} t^{i} .
\end{aligned}
$$


Rearranging gives

$$
\frac{\mathrm{d} t^{j}}{\mathrm{~d} t^{i}}=\frac{\operatorname{MRS}^{i}\left[\frac{t^{j}}{\left(t^{i}\right)^{2}} \varepsilon^{i j} \beta_{i j}+\left(1-\beta_{i j} \frac{t^{j}}{\bar{t}^{i}}\right) \frac{\partial \varepsilon^{i j}}{\partial t^{i}}\right]+\left[\left(1-\frac{\bar{K}^{i}}{K^{i}}\right)\left(\frac{\partial R^{2}(\mathbf{t})}{\partial t^{i} \partial t^{i}}\right)+\frac{\bar{K}^{i}}{\left(K^{i}\right)^{2}} \frac{\partial R(\mathbf{t})}{\partial t^{i}} \frac{\partial K^{i}}{\partial t^{i}}\right]}{\operatorname{MRS}^{i}\left[\frac{1}{t^{i}} \varepsilon^{i j} \beta_{i j}-\left(1-\beta_{i j} \frac{t^{j}}{t^{i}}\right) \frac{\partial \varepsilon^{i j}}{\partial t^{j}}\right]-\left[\left(1-\frac{\bar{K}^{i}}{K^{i}}\right) \frac{\partial^{2} R(\mathbf{t})}{\partial t^{i} \partial t^{j}}+\frac{\bar{K}^{i}}{\left(K^{i}\right)^{2}} \frac{\partial R(\mathbf{t})}{\partial t^{i}} \frac{\partial K^{i}}{\partial t^{j}}\right]}
$$

with

$$
\frac{\partial \varepsilon^{i j}}{\partial t^{j}}=-\frac{t^{i}}{\left(K^{i}\right)^{2}} \frac{\partial K^{j}}{\partial t^{i}} \frac{\partial K^{j}}{\partial t^{j}}+\frac{t^{i}}{K^{i}} \frac{\partial^{2} K^{j}}{\partial t^{i} \partial t^{j}}=-\frac{t^{i}}{\left(K^{i}\right)^{2}}[\underbrace{\frac{\partial K^{j}}{\partial t^{i}} \frac{\partial K^{j}}{\partial t^{j}}}_{<0}-K^{i} \frac{\partial^{2} K^{j}}{\partial t^{i} \partial t^{j}}]
$$

\section{Appendix 3: Example}

\section{Capital allocation}

Each firm employs the quantity of capital $K^{i}$ that maximizes its after-tax profit, i.e.

$$
\Pi_{i}=\left(b_{i}\left(a_{i}-K^{i}\right) K^{i}\right)-\left(r+t^{i}\right) K^{i}
$$

The F.O.C. for the problem in equation can be written as:

$$
K^{i}=\frac{a_{i}}{2}-\frac{t^{i}+r}{2 b_{i}}, \quad \text { with } i=1,2,3 .
$$

By combining Eq. (19) with the equality $K=\sum_{i=1}^{3} K^{i}$, we can write the demand for capital as:

$$
\begin{aligned}
K_{1} & =\Delta_{1}+\frac{-t^{1} \sum_{j \neq 1} b_{j}+b_{2} t^{3}+t^{2} b_{3}}{2 \Theta}, \\
K_{2} & =\Delta_{2}+\frac{-t^{2} \sum_{j \neq 2} b_{j}+b_{1} t^{3}+t^{1} b_{3}}{2 \Theta}, \\
K_{2} & =\Delta_{2}+\frac{-t^{2} \sum_{j \neq 2} b_{j}+b_{1} t^{3}+t^{1} b_{3}}{2 \Theta}, \\
r & =\frac{\prod_{i=1}^{3} b_{i}-\left(\sum_{i=1}^{3} a_{i}-2 K\right)-t^{3} b_{1} b_{2}-t^{1} b_{2} b_{3}-t^{2} b_{1} b_{3}}{\Theta}
\end{aligned}
$$

where $\Theta \equiv b_{2} b_{1}+b_{1} b_{3}+b_{2} b_{3}$ and $\Delta_{i} \equiv \frac{\prod_{j \neq i} b_{j}\left(2 K-\sum_{j \neq i} a_{j}\right)+b_{i} a_{i}-\sum_{j \neq i} b_{j}}{2 \Theta}$. The system of equations in (20) shows that capital allocation and the interest rate depend on all the tax rates and the technological parameters. In particular, $t^{i}\left(t^{j \neq i}\right)$ has a negative (positive) impact on $K^{i}$. Moreover, an increase in $t^{i}$ reduces $r$. 


\section{Reaction functions}

The F.O.C. for Problem (7) allows to determine the reaction function of each jurisdiction to a change in the tax rate of the other local authorities Let us consider the problem for jurisdiction 1

$$
\begin{aligned}
\operatorname{Max}_{t^{1}} U_{1}= & \alpha_{1} c_{1}+\left(1-\alpha_{1}\right)\left(g_{1}+\beta_{12} g_{2}+\beta_{13} g_{3}\right) \\
& \text { s.t. } \\
g_{1}= & t^{1} K_{1} \\
g_{2}= & t^{2} K_{2} \\
g_{3}= & t^{3} K_{3} \\
C^{1}= & b_{1}\left(a_{1}-K_{1}\right) k_{1}-\left(r+t^{1}\right) K_{1}+\theta_{1} r K
\end{aligned}
$$

The F.O.C. for the problem can be written as:

$$
\begin{aligned}
& \frac{\partial U}{\partial t^{1}}: \frac{\left(b_{3}+b_{2}\right)}{2} \frac{-2 \Theta\left(1-\alpha_{1}\right)+\alpha_{1} b_{1}\left(b_{3}+b_{2}\right)}{\Theta^{2}} t^{1} \\
& +b_{3} \frac{\Theta\left(1-\alpha_{1}\right)\left(1+\beta_{12}\right)-\alpha_{1} b_{1}\left(b_{3}+b_{2}\right)}{2 \Theta^{2}} t^{2} \\
& +b_{2} \frac{\Theta\left(1-\alpha_{1}\right)\left(1+\beta_{13}\right)-\alpha_{1} b_{1}\left(b_{3}+b_{2}\right)}{2 \Theta^{2}} t^{3} \\
& +b_{2} b_{3} \frac{\left(b_{2} b_{3}+b_{1} b_{3}+b_{2} b_{1}\right)\left(1-\alpha_{1}\left(1+\theta_{1}\right)\right)-\alpha_{1} b_{1}\left(b_{2}+b_{3}\right)}{\left(b_{2} b_{1}+b_{1} b_{3}+b_{2} b_{3}\right)^{2}} K \\
& -\frac{\left(b_{3} b_{2}\left(a_{2}+a_{3}\right)-b_{1} a_{1}\left(b_{2}+b_{3}\right)\right)\left(\Theta\left(1-\alpha_{1}\right)-\alpha_{1} b_{1}\left(b_{2}+b_{3}\right)\right)}{2 \Theta^{2}}
\end{aligned}
$$

The optimal level of $t^{1}$ conditional on the choices of $t^{2}$ and $t^{3}$ can be written as:

$$
\begin{aligned}
t^{1}= & b_{3} \frac{\alpha_{1} b_{1}\left(b_{3}+b_{2}\right)-\Theta\left(1-\alpha_{1}\right)\left(1+\beta_{12}\right)}{-\left(b_{3}+b_{2}\right)\left(2 \Theta\left(1-\alpha_{1}\right)-\alpha_{1} b_{1}\left(b_{3}+b_{2}\right)\right)} t^{2} \\
& +b_{2} \frac{\alpha_{1} b_{1}\left(b_{3}+b_{2}\right)-\Theta\left(1-\alpha_{1}\right)\left(1+\beta_{13}\right)}{-\left(b_{3}+b_{2}\right)\left(2 \Theta\left(1-\alpha_{1}\right)-\alpha_{1} b_{1}\left(b_{3}+b_{2}\right)\right)} t^{3} \\
& -2 b_{2} b_{3} \frac{\left(\Theta\left(1-\alpha_{1}\left(1+\theta_{1}\right)\right)-\alpha_{1} b_{1}\left(b_{2}+b_{3}\right)\right)}{\left(b_{3}+b_{2}\right)\left(2 \Theta\left(1-\alpha_{1}\right)-\alpha_{1} b_{1}\left(b_{3}+b_{2}\right)\right)} K \\
& +\frac{\left(b_{3} b_{2}\left(a_{2}+a_{3}\right)-b_{1} a_{1}\left(b_{2}+b_{3}\right)\right)\left(\Theta\left(1-\alpha_{1}\right)-\alpha_{1} b_{1}\left(b_{2}+b_{3}\right)\right)}{\left(b_{3}+b_{2}\right)\left(2 \Theta\left(1-\alpha_{1}\right)-\alpha_{1} b_{1}\left(b_{3}+b_{2}\right)\right)}
\end{aligned}
$$

The first derivatives of this equation allow to find the reaction functions. Analogously, we can calculate the reaction functions for $t^{2}$ and $t^{3}$. Results are presented below: 


$$
\begin{aligned}
& t^{12}=b_{3} \frac{\alpha_{1} b_{1}\left(b_{3}+b_{2}\right)-\Theta\left(1-\alpha_{1}\right)\left(1+\beta_{12}\right)}{-\left(b_{3}+b_{2}\right)\left(2 \Theta\left(1-\alpha_{1}\right)-\alpha_{1} b_{1}\left(b_{3}+b_{2}\right)\right)}, \\
& t^{13}=b_{2} \frac{\alpha_{1} b_{1}\left(b_{3}+b_{2}\right)-\Theta\left(1-\alpha_{1}\right)\left(1+\beta_{13}\right)}{-\left(b_{3}+b_{2}\right)\left(2 \Theta\left(1-\alpha_{1}\right)-\alpha_{1} b_{1}\left(b_{3}+b_{2}\right)\right)}, \\
& t^{21}=b_{3} \frac{\alpha_{2} b_{2}\left(b_{3}+b_{1}\right)-\Theta\left(1-\alpha_{2}\right)\left(1+\beta_{21}\right)}{-\left(b_{1}+b_{3}\right)\left(2 \Theta\left(1-\alpha_{2}\right)-\alpha_{2}\left(b_{2} b_{3}+b_{2} b_{1}\right)\right)}, \\
& t^{23}=b_{1} \frac{\alpha_{2} b_{2}\left(b_{3}+b_{1}\right)-\Theta\left(1-\alpha_{2}\right)\left(1+\beta_{23}\right)}{-\left(b_{1}+b_{3}\right)\left(2 \Theta\left(1-\alpha_{2}\right)-\alpha_{2}\left(b_{2} b_{3}+b_{2} b_{1}\right)\right)}, \\
& t^{31}=b_{2} \frac{\alpha_{3} b_{3}\left(b_{1}+b_{2}\right)-\Theta\left(1-\alpha_{3}\right)\left(1+\beta_{31}\right)}{-\left(b_{1}+b_{2}\right)\left(2 \Theta\left(1-\alpha_{3}\right)-\alpha_{3} b_{3}\left(b_{1}+b_{2}\right)\right)}, \\
& t^{32}=b_{1} \frac{\alpha_{3} b_{3}\left(b_{1}+b_{2}\right)-\Theta\left(1-\alpha_{3}\right)\left(1+\beta_{32}\right)}{-\left(b_{1}+b_{2}\right)\left(2 \Theta\left(1-\alpha_{3}\right)-\alpha_{3} b_{3}\left(b_{1}+b_{2}\right)\right)} .
\end{aligned}
$$

To show this, let us consider the reaction function of $t^{1}$ to a change in $t^{2}$ and $t^{3}$. Given $v_{i} \equiv b_{i}\left(\sum_{j \neq i} b_{j}\right)$ and $\Theta \equiv\left(b_{1} b_{3}+b_{2} b_{3}+b_{2} b_{1}\right)$, in "Proof of inequalities (15)" in Appendix we show that:

\section{Proof of inequalities (15)}

Let us focus on jurisdiction 1 and write the marginal effects

$$
\begin{aligned}
& t^{12}=\frac{\partial t^{1}}{\partial t^{2}}=b_{3} \frac{\Theta\left(1-\alpha_{1}\right)\left(1+\beta_{12}\right)-\alpha_{1} b_{1}\left(b_{3}+b_{2}\right)}{\left(2\left(b_{3}+b_{2}\right) \Theta\left(1-\alpha_{1}\right)+\alpha_{1} b_{1}\right)\left(b_{3}+b_{2}\right)} \\
& t^{13}=\frac{\partial t^{1}}{\partial t^{3}}=b_{2} \frac{\Theta\left(1-\alpha_{1}\right)\left(1+\beta_{13}\right)-\alpha_{1} b_{1}\left(b_{3}+b_{2}\right)}{\left(2\left(b_{3}+b_{2}\right) \Theta\left(1-\alpha_{1}\right)+\alpha_{1} b_{1}\right)\left(b_{3}+b_{2}\right)}
\end{aligned}
$$

As can be seen, both denominators are positive, while the numerator has an ambiguous sign. In particular, using $v_{1} \equiv b_{1}\left(b_{3}+b_{2}\right)$ and $\Theta \equiv\left(b_{1} b_{3}+b_{2} b_{3}+b_{2} b_{1}\right)$, we can therefore obtain:

$$
\begin{aligned}
& t^{12} \gtrless 0 \text { if } \beta_{12} \gtrless \frac{\alpha_{1}}{1-\alpha_{1}} \frac{\nu_{1}}{\Theta}-1, \\
& t^{13} \gtrless 0 \text { if } \beta_{13} \gtrless \frac{\alpha_{1}}{1-\alpha_{1}} \frac{\nu_{1}}{\Theta}-1 .
\end{aligned}
$$




\section{References}

Banzhaf, H. S., \& Chupp, B. A. (2011, January). Heterogeneous harm vs. spatial spillovers: Environmental federalism and US air pollution. Working paper 15666, National Bureau of Economic Research.

Bjorvatn, K., \& Schjelderup, G. (2002). Tax competition and international public goods. International Tax and Public Finance, 9(2), 111-120.

Boarnet, M. G. (1998). Spillovers and the locational effects of public infrastructure. Journal of Regional Science, 38(3), 381-400.

Brekke, K. R., Levaggi, R., Siciliani, L., \& Straume, O. R. (2016). Patient mobility and health care quality when regions and patients differ in income. Journal of Health Economics, 50, 372.

Brueckner, J. K., \& Saavedra, L. A. (2001). Do local governments engage in strategic property-tax competition? National Tax Journal, 54(2), 203-230.

Bucovetsky, S. (1991). Asymmetric tax competition. Journal of Urban Economics, 30(2), 167-181.

Cergas-Bocconi. (2017). Rapporto OASI 2017: Osservatorio sulle Aziende e sul Sistema sanitario Italiano. Cergas-Bocconi.

Chirinko, R. S., \& Wilson, D. J. (2017). Tax competition among U.S. states: Racing to the bottom or riding on a seesaw? Journal of Public Economics, 155, 147-163.

Devereux, M. P., Lockwood, B., \& Redoano, M. (2008). Do countries compete over corporate tax rates? Journal of Public Economics, 92(5), 1210-1235.

Egger, P., \& Raff, H. (2015). Tax rate and tax base competition for foreign direct investment. International Tax and Public Finance, 22(5), 777-810.

Fondazione GiMBE. (2019). La mobilità sanitaria interregionale nel 2017, Report Osservatorio GIMBE n.6/2019, available at: https://www.gimbe.org/osservatorio/Report_Osservatorio_GIMBE_2019.06_ Mobilita_sanitaria_2017.pdf.

Kanbur, R., \& Keen, M. (1993). Jeux sans frontières: Tax competition and tax coordination when countries differ in size. The American Economic Review, 83(4), 877-892.

Keen, M., \& Konrad, K. A. (2013). Chapter 5-the theory of international tax competition and coordination. In A. J. Auerbach, R. Chetty, M. Feldstein, \& E. Saez (Eds.), Handbook of public economics. Handbook of public economics (Vol. 5, pp. 257-328). Amsterdam: Elsevier.

Leibrecht, M., \& Hochgatterer, C. (2012). Tax competition as a cause of falling corporate income tax rates: A survey of empirical literature. Journal of Economic Surveys, 26(4), 616-648.

López, F. A., Martínez-Ortiz, P. J., \& Cegarra-Navarro, J.-G. (2017). Spatial spillovers in public expenditure on a municipal level in Spain. The Annals of Regional Science, 58(1), 39-65.

Ly, T. (2018). Sub-metropolitan tax competition with household and capital mobility. International Tax and Public Finance, 25(5), 1129-1169. https://doi.org/10.1007/s10797-018-9490-7.

Miniaci, R., Panteghini, P., \& Rivolta, G. (2018). The estimation of reaction functions under tax competition. CESifo working paper series 6928, CESifo Group, Munich.

Mintz, J., \& Tulkens, H. (1986). Commodity tax competition between member states of a federation: Equilibrium and efficiency. Journal of Public Economics, 29(2), 133-172.

Oates, W. (2002). A reconsideration of environmental federalism. In J. A. List \& A. de Zeeuw (Eds.), Recent advances in environmental economics (pp. 1-32). Cheltenham: Edward Elgar.

Oates, W. E. (2008). On the evolution of fiscal federalism: Theory and institutions. National Tax Journal, $61,313-334$.

Ogawa, H. (2007). Strategic taxation on mobile capital with spillover externality. FinanzArchiv: Public Finance Analysis, 63(1), 33-45.

Ogawa, H., \& Wildasin, D. E. (2009). Think locally, act locally: Spillovers, spillbacks and efficient decentralized policy making. American Economic Review, 99(4), 1206-1217.

Ojede, A., Atems, B., \& Yamarik, S. (2018). The direct and indirect (spillover) effects of productive government spending on state economic growth. Growth and Change, 49(1), 122-141.

Parchet, R. (2019). Are local tax rates strategic complements or strategic substitutes? American Economic Journal: Economic Policy, 11(2), 189-224.

Redoano, M. (2014). Tax competition among European countries. Does the EU matter? European Journal of Political Economy, 34, 353-371.

Revelli, F. (2005). On spatial public finance empirics. International Tax and Public Finance, 12(4), $475-492$. 
Sloboda, B. W., \& Yao, V. W. (2008). Interstate spillovers of private capital and public spending. The Annals of Regional Science, 42(3), 505-518.

Solé-Ollé, A. (2006). Expenditure spillovers and fiscal interactions: Empirical evidence from local governments in spain. Journal of Urban Economics, 59(1), 32-53.

Vrijburg, H., \& de Mooij, R. A. (2016). Tax rates as strategic substitutes. International Tax and Public Finance, 23(1), 2-24.

Wildasin, D. E. (1988). Nash equilibria in models of fiscal competition. Journal of Public Economics, 35(2), 229-240.

Wildasin, D. E., (2001, December). Externalities and bailouts: Hard and soft budget constraints in intergovernmental fiscal relations. Public Economics 0112002, EconWPA.

Wilson, J. D. (1986). A theory of interregional tax competition. Journal of Urban Economics, 19(3), 296-315.

Wilson, J. D. (1991). Tax competition with interregional differences in factor endowments. Regional Science and Urban Economics, 21(3), 423-451. special Issue Theoretical Issues in Local Public Economics.

Zodrow, G. R., \& Mieszkowski, P. (1986). Pigou, tiebout, property taxation, and the underprovision of local public goods. Journal of Urban Economics, 19(3), 356-370.

Publisher's Note Springer Nature remains neutral with regard to jurisdictional claims in published maps and institutional affiliations. 